\title{
Residual stress state in oxide dispersive steel due to irradiation by swift heavy ions
}

\author{
Vladimir Uglov ${ }^{1, a^{*}}$, Vladimir Skuratov ${ }^{2, b}$, Tatjana Ulyanenkova ${ }^{3, \mathrm{c}}$, \\ Andrei Benediktovitch ${ }^{1, d}$, Alexander Ulyanenkov ${ }^{3, e}$, Sergey Zlotski ${ }^{1, a}$ \\ ${ }^{1}$ Belarusian State University, Physical Department, Nezavisimosti av. 4, Minsk, Belarus \\ ${ }^{2}$ Flerov laboratory of nuclear reactions, Joint Institute for Nuclear Research, Joliot Curie, 6, Dubna, \\ Moscow region, Russia \\ ${ }^{3}$ Rigaku Europe SE, Am Hardtvald 11, Ettlingen, Germany

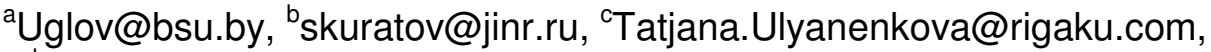 \\ dandrei.benediktovitch@atomicus.by, ${ }^{\mathrm{e}}$ Alex.Ulyanenkov@rigaku.com
}

Keywords: ODS, residual stress, ion irradiation.

\begin{abstract}
Oxide dispersive steel is a promising material for next nuclear reactors generation. Performance of this material in nuclear reactor can be modeled by means of irradiation by swift Bi ions, which are typical nuclear fusion products. Radiation damage results in microstructure alternation leading to formation of micro and macro stresses that influence the material performance. The residual stress state of ferrite matrix of the steel is investigated by XRD methodic and dependence on the irradiation dose is analyzed.
\end{abstract}

\section{Introduction}

Being considered as promising candidate materials for future reactors, oxide dispersion strengthened (ODS) steels are subject of extensive irradiation testing with various radiation sources. The dispersion of nano-sized oxides associated with the ferritic matrix confers very good creep strength at high temperature and resistance to radiation swelling at high dose [1-3]. The ferritic ODS steels have superior void swelling resistance by virtue of the inherently favorable interaction between point defects. Besides, the dispersoids also act as trapping sites for irradiation induced point defects thereby enhancing the swelling resistance. In addition, the dispersed oxide particles impede the movement of dislocations providing the required high temperature creep resistance, which is otherwise low in ferritic steels.

Energetic ions can be used to investigate the effects of neutron irradiation in reactor components. Although the damage state depends on the particle type and damage rate, simulations with ion irradiations yield answer on basic mechanisms with the considerable advantage to enable easy variations of irradiation parameters without residual activity of the samples.

In the last years, there have been considerable research efforts on development of ODS steels [4-6]. These research efforts encompass synthesis of the alloy by powder metallurgical processing methods such as mechanical alloying followed by consolidation employing hipping, forging or extrusion at high temperatures.

The addition of a small amount of Ti has been reported to be responsible for refinement of the dispersoid size [7-9] through the formation of YTi complex oxide, which in turn significantly improves creep rupture strength. It has been reported in the literature [10] that these Y-Ti complex oxide particles are exceptionally stable under irradiation environments.

In this paper we present the results of residual stress study of Fe-15Cr-2W-0.2Ti- $0.35 \mathrm{Y}_{2} \mathrm{O}_{3}$ ODS (KP123) steel irradiated with $700 \mathrm{MeV}$ Bi ions.

\section{Experimental}

The materials used in our studies were KP123 Fe-15Cr-2W-0.2Ti-0.35 $\mathrm{Y}_{2} \mathrm{O}_{3}$ ODS alloy (Kyoto University). Briefly, the pre-alloyed powder was first mechanically alloyed with $\mathrm{Y} 2 \mathrm{O} 3$ powder in 
an Argon gas atmosphere at room temperature using an attrition type ball mill. The powder was then sealed in a stainless-steel can and degassed at $400{ }^{\circ} \mathrm{C}$ in $0.1 \mathrm{~Pa}$ pressure. The canned powders were subsequently consolidated by a hot extrusion technique at $1150{ }^{\circ} \mathrm{C}$. After the extrusion, the consolidated ODS steel was thermally treated at $1150{ }^{\circ} \mathrm{C}$ for 1 hour. The samples $(10 \times 10 \times 1 \mathrm{~mm})$ of the as-fabricated ODS steel for XRD examination were prepared by a standard procedure that includes slicing, grinding, and polishing the recovered fragments with the samples surface approximately perpendicular to the loading axis.

High energy ion irradiations at room temperature were performed at the U-400 cyclotrons at FLNR JINR, Dubna. Ion beam homogeneity, better than 5\%, on irradiating specimen surface has been reached using beam scanning in horizontal and vertical directions. Ion fluence and integral dose of $700 \mathrm{MeV} \mathrm{Bi}$ ions were $6.15 \times 10^{12} \mathrm{~cm}^{-2}$ and $4.9 \times 10^{-4} \mathrm{dpa}$, respectively. The heating of irradiating samples was about a few degrees of centigrade. The dpa/ion $\left(8 \times 10^{-8} \mathrm{dpa} / \mathrm{s} \mathrm{cm}^{-2}\right)$ was determined as a number of vacancies/ion/angstrom, calculated using SRIM code for $E_{\mathrm{d}}=40 \mathrm{eV}$, divided per number of ions in the layer with area of one $\mathrm{cm}^{2}$ and one angstrom thickness.

Cross-sectional TEM specimens were performed using a JEOL JEM $2100 \mathrm{LaB}_{6}$ transmission electron microscope operating at $200 \mathrm{kV}$.

The XRD experiments were performed on a five-circle SmartLab diffractometer from Rigaku equipped with a $9 \mathrm{~kW}$ rotating anode using $\mathrm{Cu} \mathrm{K \alpha}$ radiation $(\lambda=1.54056 \AA)$. X-ray diffraction stress measurements were carried out in parallel-beam geometry to avoid any influence of the sample surface quality on the peak position. The diffractometer was carefully aligned and checked on the $\mathrm{LaB}_{6}$ standard sample.

The diffractometer is equipped with cross-beam optic (CBO, patented Rigaku Corp.) collimating the incident beam and equatorial divergence of the diffracted beam is controlled by a $0.5^{\circ} \mathrm{PSA}$. For lateral collimation the $5^{\circ}$ Soller Slits on the both sides were used.

XRD stress analysis was performed on unirradiated and ion-irradiated samples using the $\sin ^{2} \psi$ method. The diffraction lines of two peaks with the Bragg angles equal to $44.5^{\circ}$ and $81.9^{\circ}$ are recorded at various tilt, $\psi$ and rotation, $\varphi$ angles. For every peak the set of scans was performed for $\varphi=0^{\circ}, 45^{\circ}, 90^{\circ}, 180^{\circ}, 225^{\circ}, 270^{\circ}$ and inclination angle $\psi$ was changing from $0^{\circ}$ to $45^{\circ}$ with a step of $5^{\circ}$. The value of $\mathrm{a}_{0}$ obtained by XRD studies of annealing at $900^{\circ} \mathrm{C}$ ODS steel was used as a stress-free lattice parameter.

\section{Results and Discussion}

Typical microstructures of unirradiated K123-ODS steel are shown in Fig. 1. Here, elongated grains (size are about $0.5 \mu \mathrm{m}$ ) and dense oxide nanoparticles were observed. The oxide nanoparticle sizes in K123-ODS are typically ranging from 1-2 $\mathrm{nm}$ to $25 \mathrm{~nm}$.

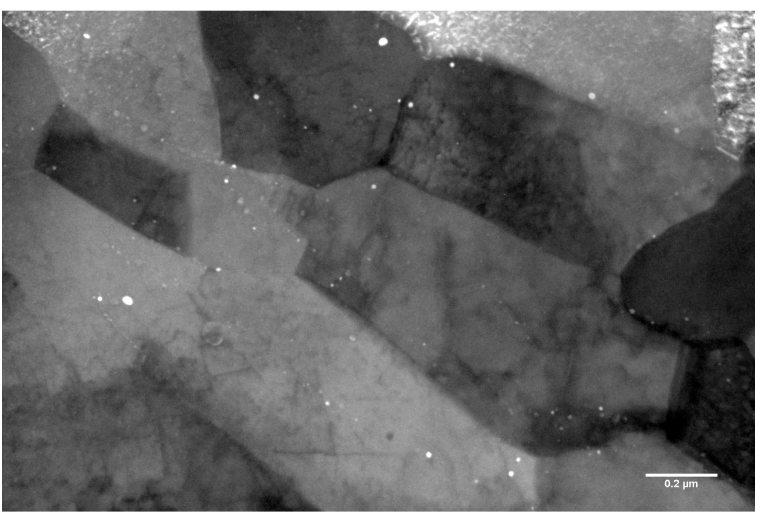

a)

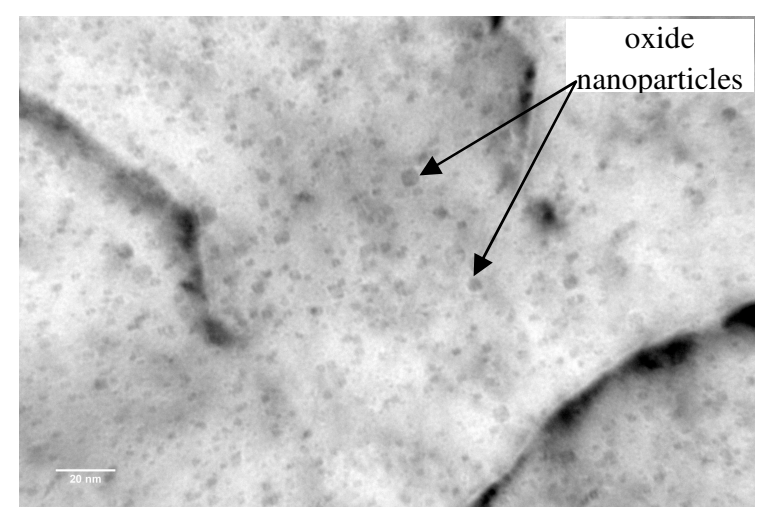

b)

Figure 1. Dark- (a) and bright- (b) field TEM image of unirradiated ODS steel.

Diffraction peaks belonging to doped ferrite $\alpha-\mathrm{Fe}(\mathrm{C}, \mathrm{Me})$, which is a solid solution of carbon and alloying elements $(\mathrm{Me}=\mathrm{Cr}, \mathrm{W}, \mathrm{Ti})$, are shifted to the small angles relative to $\alpha$-Fe (see Fig. 2). 
Moreover, the lattice parameter of $\alpha-\mathrm{Fe}(\mathrm{C}, \mathrm{Me})$ is increased by $0.46 \%$. This is due to the volume effect of the size factor of alloying elements in relation to the basic matrix.

The stress investigations of samples were carried out by $\sin ^{2} \psi$ method for diffraction peaks of $\alpha$-Fe $(\mathrm{C}, \mathrm{Me})(110)$ and (211). The elastic constants for both reflections are the same since the parameter $\Gamma=\frac{h^{2} k^{2}+k^{2} l^{2}+l^{2} h^{2}}{\left(h^{2}+k^{2}+l^{2}\right)^{2}}$, responsible for hkl dependence of x-ray elastic constants, is the same for both reflections.

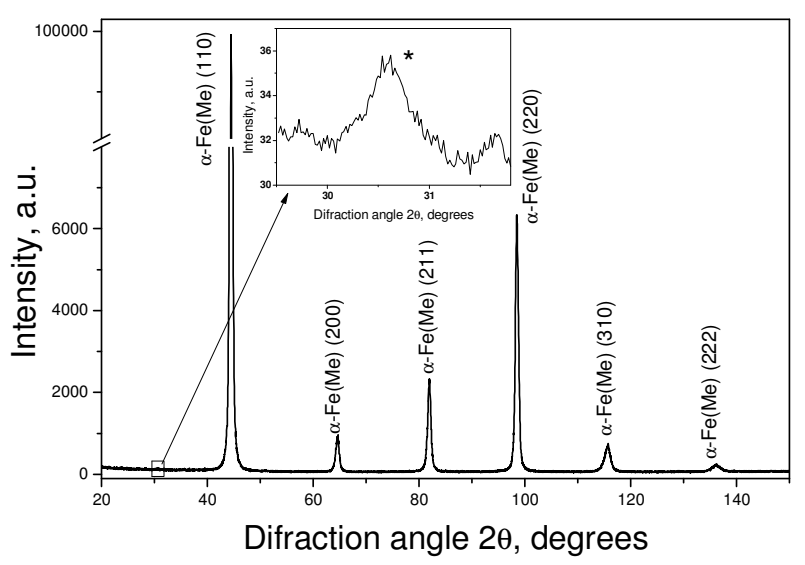

Figure 2. XRD pattern from ferritic matrix in unirradiated ODS steel. The phase of Y-Ti complex oxide is marked by *.

Analysis of the residual stress in polycrystalline materials is based on the measured positions of one or more hkl reflections at different angles of inclination $\psi$ and rotation $\phi$ of diffraction vector relative to the normal sample. According to these data, the corresponding lattice strain can be calculated from

$$
\varepsilon_{\varphi \psi}^{h k l}=\frac{a_{\phi \psi}-a_{0}}{a_{0}}
$$

Here $\mathrm{a}_{0}$ is a stress-free lattice parameter and $\mathrm{a}_{\varphi \psi}$ are the measured lattice values.

In general, in the case of the sample with macroscopic anisotropy of the elastic properties and the presence of a pronounced texture, the residual stress tensor is described by the diffraction coefficients of stress (X-ray stress factors) [11]. Without the texture, this dependence can be represented as:

$$
\begin{gathered}
\varepsilon_{\varphi \psi}^{h k l}=\frac{1+v^{h k l}}{E^{h k l}}\left[\sigma_{11} \cos ^{2} \varphi+\sigma_{12} \sin (2 \varphi)+\sigma_{22} \sin ^{2} \varphi-\sigma_{33}\right] \sin ^{2} \psi+ \\
+\frac{1+v^{h k l}}{E^{h k l}}\left[\sigma_{13} \cos \varphi+\sigma_{23} \sin \varphi\right] \sin (2 \psi)+\frac{1+v^{h k l}}{E^{h k l}} \sigma_{33}-\frac{v^{h k l}}{E^{h k l}}\left(\sigma_{11}+\sigma_{22}+\sigma_{33}\right) .
\end{gathered}
$$

Equation (2) is a generalization of Hooke's law to the case of 3 measurements recorded in a tensor form in the sample coordinate system. Here $\sigma_{i j}$ is the stress tensor components, $\mathrm{v}^{\mathrm{hkl}}$ и $\mathrm{E}^{\mathrm{hkl}}$ are an elastic constants depending on the selected reflex. Expression in the first square brackets is the slope of the curve, and secondary represents her cleavage [12].

Equation (2) is a linear equation in six unknowns, $\sigma_{11}, \sigma_{12}, \sigma_{22}, \sigma_{33}, \sigma_{13}, \sigma_{23}$, and may be solved exactly if $a_{\phi \psi}$ is measured along six independent directions. In this work we use the following procedures.

The parameters $a_{1}, a_{2}$ might be defined using following expressions 


$$
\begin{gathered}
a_{1}=\frac{1}{2}\left[\varepsilon_{\phi \psi}+\varepsilon_{\phi+180 \psi}\right]=\left[\frac{a_{\phi \psi}+a_{\phi+180 \psi}}{2 a_{0}}-1\right]=\frac{1+v}{E}\left[\sigma_{11} \cos ^{2} \varphi+\sigma_{12} \sin (2 \varphi)+\sigma_{22} \sin ^{2} \varphi-\sigma_{33}\right] \sin ^{2} \psi+ \\
+\frac{1+v}{E} \sigma_{33}-\frac{v}{E}\left(\sigma_{11}+\sigma_{22}+\sigma_{33}\right) \\
a_{2}=\frac{1}{2}\left[\varepsilon_{\phi \psi}-\varepsilon_{\phi+180 \psi}\right]=\left[\frac{a_{\phi \psi}-a_{\phi+180 \psi}}{2 a_{0}}\right]=\frac{1+v}{E}\left[\sigma_{13} \cos \varphi+\sigma_{23} \sin \varphi\right] \sin (2 \psi) .
\end{gathered}
$$

Equations (3-4) predict a linear variation of $a_{1}$ with $\sin ^{2} \psi$. Similarly, parameter $a_{2}$ varies linearly with $\sin 2 \psi$. The $\mathrm{a}_{\phi \psi}$ data were obtained at three rotation angles $\phi\left(0^{\circ}, 45^{\circ}, 90^{\circ}\right)$, and then $\mathrm{a}_{1}$ vs. $\sin ^{2} \psi$ and $\mathrm{a}_{2}$ vs. $\sin 2 \psi$ were plotted for all inclination angles $\psi$. By the linear approximation the curves for the stress tensor of unirradiated and irradiated Bi ODS steel were calculated.

For calculations the values of the elastic constants were used for $\alpha$-Fe $\left(v^{110}=v^{211}=0.28\right.$ and $\left.\mathrm{E}^{110}=\mathrm{E}^{211}=220 \mathrm{GPa}\right)$ and the lattice parameter was determined as $\mathrm{a}_{0}=(2.8748 \pm 0.0001) \mathrm{nm}$. The results are shown in the Table 1.

Table 1. The stress tensor of unirradiated and irradiated by Bi ions ODS steel.

\begin{tabular}{|c|c|c|c|c|c|c|}
\hline & $\sigma_{11}[\mathrm{MPa}]$ & $\sigma_{12}[\mathrm{MPa}]$ & $\sigma_{13}[\mathrm{MPa}]$ & $\sigma_{22}[\mathrm{MPa}]$ & $\sigma_{23}[\mathrm{MPa}]$ & $\sigma_{33}[\mathrm{MPa}]$ \\
\hline Unirradiated & $-280 \pm 10$ & $-6 \pm 2$ & $70 \pm 0.6$ & $-330 \pm 20$ & $-6.2 \pm 0.6$ & $330 \pm 20$ \\
\hline $6.15 \times 10^{12}\left[\mathrm{~cm}^{-2}\right]$ & $-290 \pm 10$ & $30 \pm 10$ & $2.8 \pm 0.5$ & $-300 \pm 20$ & $-1.0 \pm 0.2$ & $300 \pm 10$ \\
\hline
\end{tabular}

It was found that the unirradiated sample of ODS steel KP-123 has a compressive $\left(\sigma_{11}=-\right.$ $\left.280 \mathrm{MPa}, \sigma_{22}=-330 \mathrm{MPa}\right)$ and tensile stress $\left(\sigma_{33}=330 \mathrm{MPa}\right)$.

Irradiation with high-energy ions (dose of $6.15 \cdot 10^{12} \mathrm{Bi} / \mathrm{cm}^{2}$ ) leads to a slight reduction in the tensile stress level $\sigma_{33}$ in the ferrite matrix, which is apparently due to the low dose ion irradiation for such bulk samples.

\section{References}

[1]S. Ukai, S. Mizuta, M. Fujiwara, T. Okuda, T. Kobayashi, Development of 9Cr-ODS Martensitic Steel Claddings for Fuel Pins by means of Ferrite to Austenite Phase Transformation, J. Nucl. Sci. Technol. 39 (2002) 778-788.

[2]A. Alamo, V. Lambard, X. Averty, M.-H. Mathon, Assessment of ODS-14\%Cr ferritic alloy for high temperature applications, J. Nucl. Mater. 329-333 (2004) 333-337.

[3]Y. de Carlan, J.-L. Bechade, P. Dubuisson, J.-L. Seran, P. Billot, A. Bougault, T.Cozzika, S. Doriot, D. Hamon, J. Henry, M. Ratti, N. Lochet, D. Nunes, P. Olier, T.leblond, M.-H. Mathon, CEA developments of new ferritic ODS alloys for nuclear applications, J. Nucl. Mater. 386-388 (2009) 430-432.

[4]K.L. Murty and I. Charit, Structural materials for Gen-IV nuclear reactors: challenges and opportunities, J. Nucl. Mater. 383 (2008) 189-195.

[5]M.J. Alinger, G.R. Odette and D.T. Hoelzer, On the role of alloy composition and processing parameters in nanocluster formation and dispersion strengthening in nanostructured ferritic alloys, Acta Mater. 57 (2009) 392-406.

[6]K. Verhiest, A. Almazouzi, N. De. Wispelaere, R. Petrov and S. Claessens, Development of oxides dispersion strengthened steels for high temperature nuclear reactor applications, J. Nucl. Mater. 385 (2009) 308-311.

[7]M.K. Miller, K.F. Russel and D.T. Hoelzer, Characterization of precipitates in MA/ODS ferritic alloys, J. Nucl. Mater. 351 (2006) 261-268.

[8]M. Ratti, D. Leuvrey, M.H. Mathon and Y.De Carlan, Influence of titanium on nano-cluster (Y, Ti, O) stability in ODS ferritic materials, J. Nucl. Mater. 386-388 (2009) 510-543. 
[9]L. Zhang, S. Ukai, T. Hoshimo, S. Hayashi and X. Qu, Y2O3 evolution and dispersion refinement in Co-base ODS alloys, Acta Mater. 57 (2009) 3671-3682.

[10] H. Kishimoto, R. Kasada, O. Hashitomi and A. Kimura, Stability of Y-Ti complex oxides in $\mathrm{Fe}-16 \mathrm{Cr}-0.1 \mathrm{Ti}$ ODS ferritic steel before and after heavy-ion irradiation, J. Nucl. Mater. 386-388 (2009) 533-536.

[11] U. Welzel, J. Ligot, P. Lamparter, A.C. Vermeulen, E.J. Mittemeljer, Stress analysis of polycrystalline thin films and surface regions by X-ray diffraction, Appl. Cryst. 38 (2005) 1-29.

[12] H.A. Jejn, Multicomponent and multiphase hard coatings for tribological applications, Surf.Coat.Technol. 131 (2000) 433-440. 